\title{
Place Attachment Masyarakat di RW 04, Kelurahan Polehan, Kota Malang
}

\author{
Community Place Attachment in RW 04, Kelurahan Polehan, Kota Malang
}

\author{
Efma Haryani ${ }^{1}$, Wara Indira Rukmi ${ }^{1}$ and Deni Agus Setyono ${ }^{1}$
}

Diterima: 14 Juni 2019 Disetujui: 1 April 2020

\begin{abstract}
Abstrak: Area permukiman di RW 04 ditetapkan sebagai salah satu kawasan prioritas dalam penanganan permukiman kumuh oleh Pemerintah Kota Malang. Permukiman kumuh di RW 04 disebabkan oleh faktor permukiman padat, tak layak huni dan pencemaran lingkungan oleh aktivitas masyarakat sehingga Pemerintah Kota Malang melakukan upaya pengentasan permukiman kumuh dan sebagai upaya untuk mendukung Program 100-0-100. Upaya pengentasan permukiman kumuh dilakukan melalui Program PLPBK (Penataan Lingkungan Permukiman Kumuh Berbasis Komunitas) yang dapat mempengaruhi place attachment masyarakat sehingga kesan masyarakat terhadap RW 04 mengalami perubahan dari kesan kumuh menjadi kesan yang bersih dan asri. Perubahan lingkungan RW 04 dapat memperkuat place attachment sehingga masyarakat merasa nyaman, bangga dan aman. Tujuan penelitian ini adalah untuk mengidentifikasi place attachment masyarakat di RW 04, Kelurahan Polehan, Kota Malang dan analisis yang digunakan adalah statistik deskriptif. Hasil penelitian menunjukkan bahwa masyarakat akan memiliki place attachment yang kuat selama responden memiliki keinginan untuk mengembangkan place attachment melalui pengalaman, intensitas interaksi sosial, kepemilikan objek yang berharga, tindakan atau usaha untuk mengkontrol lingkungan, lamanya waktu yang dihabiskan, tidak melakukan migrasi, dan RW 04 yang dapat menggantikan kenangan masa anak-anak bagi pendatang. Place attacment yang kuat juga dipengaruhi oleh karakteristik responden sehingga cenderung memiliki keinginan untuk tetap tinggal di RW 04.
\end{abstract}

Kata kunci: place Attachment, permukiman kumuh, PLPBK

\begin{abstract}
The settlement area in RW 04 is determined as one of the priority areas that the Government of Malang City should overcome from slum problems. Slum factors in RW 04 are caused by density settlement, unlivable residential area, and environmental pollution by the community activities. Therefore, the local government creates a program to diminish the slum and to support the 100-0-100 Program as well. The effort to overcome the slum problems is done through a progam called PLPBK (Penataan Lingkungan Permukiman Berbasis Komunitas) which can affect community place attachment. Hence, the community image of RW 04 would change from a slum into a clean and beautiful residential area. The environmental transformation in RW 04 could strengthen place attachment and as a result, the people feel more comfortable, proud, and safe. This study aims to identify community place attachment in RW 04, Polehan, Malang and the analysis used is descriptive statistics. This research shows that the community would have a strong place attachment as long as the respondents have the willingness to develop place attachment through experience, intensity of social interaction, the possession of valuable object, action or effort to control the environment, the length of resident, do not migrate, and RW 04 that is able to
\end{abstract}

\footnotetext{
${ }^{1}$ Perencanaan Wilayah dan Kota, Universitas Brawijaya
} 
replace the childhood memories of immigrant. The strong place attachment is affected by the respondents characteristics as well, and as a result, they tend to have willingness to live in RW 04.

Keywords: place attachment, slums area, PLPBK

\section{PENDAHULUAN}

Permukiman kumuh di Kota Malang terdiri dari 29 kelurahan yang salah satunya adalah Kelurahan Polehan. Kelurahan Polehan menjadi prioritas dalam penanganan permukiman kumuh berdasar SK Walikota Malang Nomor 86 Tahun 2015 tentang Permukiman Kumuh. Kelurahan Polehan memiliki kepadatan penduduk yang tinggi sebesar 158 jiwa/Ha dengan tingkat kepadatan bangunan 104 unit/Ha (Pemerintah Kota Malang, 2015). RW 04 merupakan permukiman kumuh di Kelurahan Polehan yang terdapat masalah tentang pencemaran lingkungan akibat dari aktivitas masyarakat seperti pembuangan sampah ke sungai (Rofiana, 2015), aktivitas MCK (Mandi Cuci Kakus) di sungai yang karena tidak memiliki MCK individu dan air tanah yang sudah tercemar. Pemerintah Kota Malang melakukan upaya dalam mengatasi permasalahan di permukiman kumuh Kelurahan Polehan dengan menerapkan PLPBK (Penataan Lingkungan Permukiman Berbasis Komunitas) berdasarkan dokumen RTPLP (Rencana Tindak Penataan Lingkungan Permukiman) Kelurahan Polehan Tahun 2014-2024. Program PLPBK memiliki tujuan mewujudkan perbaikan kualitas hidup masyarakat miskin melalui penataan lingkungan permukiman yang teratur, aman dan sehat.

Program PLPBK menjadikan perubahan dari permukiman kumuh menjadi permukiman yang bersih, asri dan menjadi lebih baik dari sebelu pelaksanaan Program PLPBK. Perubahan pada lingkungan mempengaruhi perasaan kenyamanan dan keamanan masyarakat. Masyarakat juga merasa bahwa RW 04 merupakan tempat yang tidak dapat digantikan untuk menunjang aktivitas dan tujuan masyarakat karena Lokasi RW 04 merupakan lokasi yang dekat dengan kawasan perdagangan dan jasa sehingga memudahkan untuk memenuhi kebutuhan masyarakat. Kawasan yang mendukung kebutuhan masyarakat juga menjadikan masyarakat memiliki keinginan untuk tetap tinggal di lingkungan RW 04.

Program PLPBK dapat mempengaruhi place attachment (keterikatan terhadap tempat) masyarakat sehingga program tersebut dapat melemahkan atau menguatkan keterikatan antara masyarakat dengan suatu tempat. Place attachment merupakan ikatan emosional manusia dengan seting lingkungan yang dapat dipengaruhi oleh pengalaman (Altman \& Low, 1992). Place attachment juga dapat dilihat melalui place identity (identitas tempat), place dependence (ketergantungan terhadap tempat), affective attachment (ikatan afektif) dan social bonding (ikatan sosial) (Wynveen, Kyle, \& Sutton, 2012). Place attachment manusia dapat terjadi pada tempat tinggal, lingkungan, tujuan rekreasi dan pemandangan (Kaltenborn \& Bjerke, 2002). Keterikatan terhadap tempat juga memiliki konsep yang multidimensional yang terbagi menjadi dimensi pelaku yaitu merupakan hubungan manusia dengan suatu tempat yang dikategorikan menjadi pelaku individu dan pelaku kelompok, dimensi tempat yaitu merupakan dimensi yang berpengaruh secara langsung terhadap tempat itu sendiri yang dapat diklasifikasikan menjadi aspek fisik dan aspek sosial serta dimensi psikologi yaitu keterikatan yang tidak hanya memiliki fokus pada hubungan yang terjadi antara individual atau kelompok pada suatu tempat namun meninjau interaksi antara manusia dengan lingkungan secara alami yang dapat diklasifikasikan menjadi afektif, kognitif dan perilaku (Scannell \& Gifford, 2010).

Penelitian tentang place attachment sudah pernah dilakukan sebelumnya dengan menggunakan metode studi literatur sehingga menghasilkan definisi suatu konsep dan pengembangan kerangka sintesis dari berbagai macam definisi place attachment yang disebut sebagai The Tripartite Model of Place Attachment. The Tripartite Model of Place 
Attachment dijadikan sebagai acuan dalam penelitian hubungan atau ikatan yang terjadi antara manusia dengan tempat atau disebut place attachment. Place attachment masyarakat di RW 04, Kelurahan Polehan, Kota Malang memiliki fokus pada permukiman kumuh sehingga dapat diketahui pengaruh Program PLPBK pada keterikatan antara masyarakat dengan RW 04. Penelitian ini juga dilakukan untuk pengembangan program PLPBK sehingga program-program menjadi tepat sasaran yang membuat masyarakat menjadi lebih nyaman serta memiliki keinginan untuk tetap tinggal di RW 04. Penelitian ini juga dapat mendukung pencapaian RPJMN (Rencana Pembangunan Jangka Menengah Nasional) Tahun 2015-2019 yang menetapkan program pengentasan permukiman kumuh berupa program 100-0-100 dengan indikator ketersediaan pelayanan air minum sebesar $100 \%$, pengurangan jumlah rumah kumuh sebesar $0 \%$ dan ketersediaan pelayanan sanitasi sebesar $100 \%$.

\section{METODE PENELITIAN}

\section{Lokasi Penelitian}

Ruang lingkup wilayah pada penelitian ini yaitu pada RW 04 di Kelurahan Polehan karena memiliki fokus pada wilayah yang telah diselenggarakan Program PLPBK yang menjadi prioritas Pemerintah Kota Malang dalam penanganan permukiman kumuh. Berikut merupakan peta wilayah penelitian di RW 04, Kelurahan Polehan, Kota Malang pada Gambar 1.

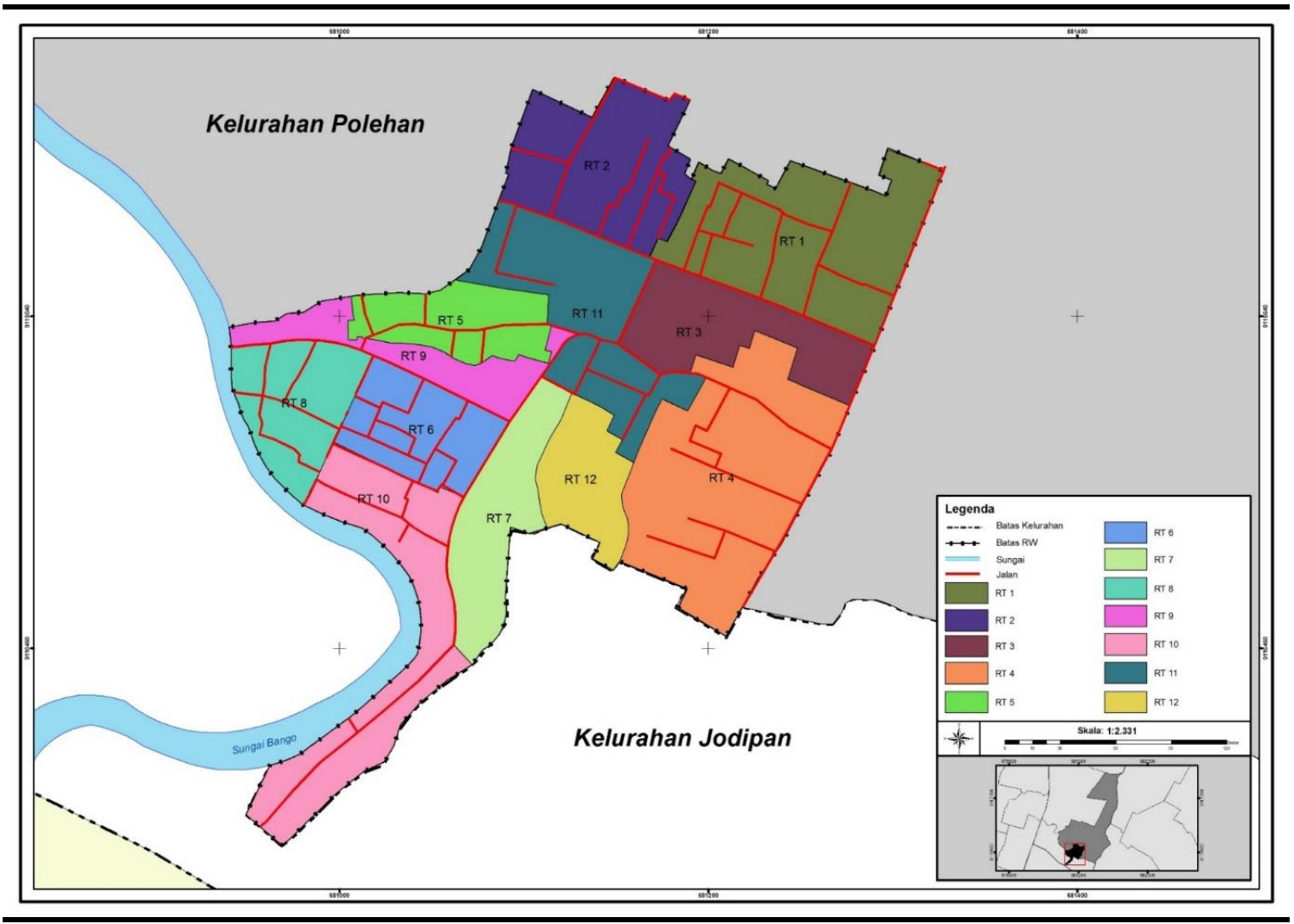

Gambar 1. Peta Wilayah Penelitian RW 04, Kelurahan Polehan, Kota Malang 


\section{Penentuan Sampel}

Pengambilan sampel yang digunakan dalam penelitian ini adalah teknis cluster sampling yang kemudian dipilih dengan menggunakan simple random sampling. Simple random sampling dengan menggunakan Isaac Michael sebanyak $357 \mathrm{KK}$ serta responden ibu rumah tangga sebanyak 16 responden.

\section{Tahapan Analisis}

Tahapan analisis yang digunakan yaitu Statistik Deskriptif digunakan dengan menggunakan tabel frekuensi untuk mengidentifikasi keterikatan masyarakat terhadap RW 04 melalui Software SPSS yang dapat dijelaskan sebagai berikut pada Tabel 1.

Table 1. Data Place Attachment

\begin{tabular}{|c|c|}
\hline Parameter & Kategorikal \\
\hline \multirow{3}{*}{ Kenangan pada masa anak-anak } & 1. Bertualang \\
\hline & 2. Berfantasi \\
\hline & 3. Bermain \\
\hline \multirow[b]{2}{*}{ Realisasi } & 1. Mengikuti kegiatan rutin/mengontrol lingkungan \\
\hline & 2. Tidak mengikuti kegiatan/mengontrol lingkungan \\
\hline \multirow{2}{*}{ Aktivitas lokal } & 1. Perayaan kesenian \\
\hline & 2. Perayaan agama \\
\hline Kesamaan (similarity) & 1. Memperbaiki lingkungan melalui program PLPBK \\
\hline \multirow{2}{*}{ Kedekatan (proximity) } & 1. Tempat tinggal dalam RT yang sama \\
\hline & 2. Tempat tinggal dalam RT yang beda \\
\hline & 1. $1-2$ kali \\
\hline \multirow{2}{*}{ Keakraban (familiarity) } & 2. $3-4$ kali \\
\hline & 3. Setiap hari \\
\hline \multirow{2}{*}{ Kemudahan akses } & 1. Mudah diakses \\
\hline & 2. Tidak Mudah diakses \\
\hline \multirow{5}{*}{ Kualitas lingkungan } & 1. Tidak Baik \\
\hline & 2. Kurang Baik \\
\hline & 3. Cukup Baik \\
\hline & 4. Baik \\
\hline & 5. Sangat Baik \\
\hline \multirow{5}{*}{$\begin{array}{l}\text { Periode hadirnya suatu pengalaman pada suatu } \\
\text { tempat }\end{array}$} & 1. TK (2-5 tahun) \\
\hline & 2. $\mathrm{SD}(6-11$ tahun $)$ \\
\hline & 3. SMP (12-14 tahun) \\
\hline & 4. SMA (15-18 tahun) \\
\hline & 5. Lainnya \\
\hline \multirow{4}{*}{ Jenis perasaan keakraban pada suatau tempat } & 1. Kenyamanan \\
\hline & 2. Kebangaan \\
\hline & 3. Perasaan setia kawan \\
\hline & 4. Menikmati fungsi tempat \\
\hline & 1. Autobiografi/ menggambar-kan lingkungan \\
\hline Jenis kegiatan pada ingatan & $\begin{array}{l}\text { 2. Ambivalensi/tindakan yang dilakukan untuk } \\
\text { mempertahankan tempat atau objek }\end{array}$ \\
\hline \multirow{2}{*}{$\begin{array}{l}\text { Jenis kegiatan yang telah mengalami } \\
\text { perpindahan }\end{array}$} & 1. Menciptakan interior \\
\hline & 2. Merenung-kan kenangan kembali \\
\hline \multirow{2}{*}{ Jenis kelamin } & 1. Laki-laki \\
\hline & 2. Perempuan \\
\hline \multirow{2}{*}{ Usia } & 1. Tidak Produktif \\
\hline & 2. Produktif \\
\hline \multirow{2}{*}{ Jumlah anggota keluarga } & 1. $<4$ \\
\hline & 2. $>5$ \\
\hline \multirow{5}{*}{ Jumlah lama tinggal } & 1. $<5$ tahun \\
\hline & 2. 5-13 tahun \\
\hline & 3. 14-22 tahun \\
\hline & 4. 23-31 tahun \\
\hline & 5. $32-40$ tahun \\
\hline \multirow{2}{*}{ Wilayah tempat lahir } & 1. Luar Pulau Jawa \\
\hline & 2. Pulau Jawa \\
\hline
\end{tabular}




\begin{tabular}{|c|c|}
\hline Parameter & Kategorikal \\
\hline \multirow{4}{*}{ Jenis pekerjaan } & 1. Tidak berkerja \\
\hline & 2. Pensiunan \\
\hline & 3. Informal \\
\hline & 4. Formal \\
\hline \multirow{5}{*}{ Tingkat pendidikan } & 1. Tidak sekolah \\
\hline & 2. $\mathrm{SD}$ \\
\hline & 3. SMP \\
\hline & 4. SMA \\
\hline & 5. S1 \\
\hline \multirow{2}{*}{ Tingkat pendapatan } & 1. Dibawah UMR \\
\hline & 2. Diatas UMR \\
\hline \multirow{6}{*}{ Agama } & 1. Kristen \\
\hline & 2. Katholik \\
\hline & 3. Hindu \\
\hline & 4. Budha \\
\hline & 5. Khong $\mathrm{Hu} \mathrm{Chu}$ \\
\hline & 6. Islam \\
\hline \multirow{3}{*}{ Jenis kepemilikan rumah } & 1. Sewa/kontrak \\
\hline & 2. Ahli waris \\
\hline & 3. Milik pribadi \\
\hline \multirow{2}{*}{ Jumlah migrasi } & 1. Pernah migrasi \\
\hline & 2. Tidak pernah migrasi \\
\hline \multirow{3}{*}{ Jumlah jam kerja } & 1. Lebih dari standar jam kerja \\
\hline & 2. Standar jam kerja \\
\hline & 3. Tidak kerja \\
\hline \multirow{2}{*}{ Pengetahuan tentang program } & 1. Tahu program \\
\hline & 2. Tidak tahu program \\
\hline
\end{tabular}

\section{HASIL DAN PEMBAHASAN}

\section{Dimensi Pelaku}

Dimensi pelaku dapat melibatkan hubungan personal antara manusia terhadap suatu tempat yang dipengaruhi oleh pengalaman manusia (Scannell \& Gifford, 2010; Hinds \& Sparks, 2008; Kilinç, 2006) yang dirasakan pada masa anak-anak sehingga memiliki keinginan untuk mengeksplorasi lebih luas suatu objek (Morgan, 2010). Kondisi eksisting masyarakat menunjukkan bahwa pengalaman pada masa anak-anak dapat mempengaruhi rasa keterikatan masyarakat terhadap ruang yang didominasi oleh pengalaman bermain sebanyak 52\%. Kegiatan bermain pada masa anak-anak didominasi di Sungai Bango sebanyak 55,2\%. Sungai Bango merupakan sungai yang melintasi RW 04, Kelurahan Polehan sehingga masyarakat merasa bahwa Sungai Bango merupakan objek yang dimiliki secara bersama-sama serta perlu untuk dijaga agar tetap menjadi bersih seperti memori kenangan pada masa anak-anak.

Masyarakat yang memiliki pengalaman dalam jangka waktu yang lama maka akan menjadikan suatu tempat menjadi bermakna serta dapat menjadi bagian identitas manusia (Kilinc, 2006) seiring dengan lamanya waktu yang dihabiskan pada suatu tempat (Casakin, Hernández, \& Ruiz, 2015; Rollero \& De Piccoli, 2010). Masyarakat yang memiliki keterikatan pada Sungai Bango pada umumnya berasal dari RW 04 karena pengalaman pada masa anak-anak di Sungai Bango serta lamanya waktu yang dihabiskan masyarakat pada RW 04 menjadikan ikatan yang lebih kuat pada RW 04. Keterikatan masyarakat pada Sungai Bango juga dapat dilihat bahwa masyarakat melihat Sungai Bango sebagai objek yang dimiliki secara bersama-sama serta dapat merepresentasikan tempat asal responden yaitu sebagai penduduk asal RW 04 dan mengidentitaskan Sungai Bango menjadi bagian dari identitas masyarakat RW 04. Interaksi masyarakat juga dapat mempengaruhi keterikatan manusia terhadap suatu tempat (Lewicka, 2010). Interaksi masyarakat dipermudah oleh kesamaan budaya karena masyarakat RW 04 didominasi oleh Suku Jawa sebanyak 99,7\%. Interaksi masyarakat juga didukung oleh perayaan yang 
sering dilakukan yaitu kegiatan perayaan 17 Agustusan di Jalan Poros Utama sebanyak 42,9\%. Kondisi eksisting pada RW 04, Kelurahan Polehan menunjukkan bahwa individu akan semakin melekat atau memiliki place attachment yang kuat seiring dengan semakin sering mengalami pengalaman di RW 04 atau pengalaman yang melekat pada masa anakanak serta semakin sering interaksi sosial melalui perayaan yang sering dilakukan. Berikut merupakan dimensi pelaku yang dapat dilihat pada Tabel 2.

Table 2. Dimensi Pelaku

\begin{tabular}{lc}
\hline Place Attachment Masyarakat RW 04 & Persentase \\
\hline Kegiatan terhadap objek yang dimiliki & $52.0 \%$ \\
Bermain & \\
Objek yang dimiliki & $55.2 \%$ \\
Sungai & \\
Tempat kelahiran & $99.7 \%$ \\
Pulau Jawa & \\
Perayaan yang Sering Dilakukan & $59.5 \%$ \\
17 Agustusan & \\
Tempat Diselenggarakan Perayaan & $42.9 \%$ \\
\hline
\end{tabular}

\section{Dimensi Tempat}

Dimensi tempat yang dapat diklasifikasikan menjadi dua aspek yaitu aspek sosial dan aspek fisik. Aspek sosial yang dapat ditinjau melalui daya tarik interpersonal yaitu kesamaan, kedekatan dan keakraban (Dayakisni \& Hudainah, 2015). Aspek fisik juga dapat ditinjau melalui rootedness atau daya lekat. Rootedness merupakan keterikatan manusia terhadap fisik yang terbentuk melalui ideological rootedness (kelekatan ideologi) dan everday rootedness (kelekatan sehari-hari) (Scannell \& Gifford, 2010).

Kondisi eksisting pada aspek sosial dapat dilihat berdasarkan daya tarik interpersonal sehingga melalui kesamaan, kedekatan dan keakraban sehingga dapat memunculkan kepemilikan tujuan yang sama dan memiliki keinginan untuk mewujudkan secara bersama-sama. Tujuan bersama timbul akibat dari kesamaan pikiran sehingga mempengaruhi keikutsertaan dalam Program PLPBK untuk mewujudkan lingkungan permukiman yang teratur, aman dan sehat. Masyarakat RW 04 yang memiliki tujuan yang sama dengan warga lainnya sebesar 49,3\% yang didominasi oleh hubungan Ketua RT/RW sebanyak 31,9\%. Ketua RT/RW memiliki andil yang besar dalam menghimbau masyarakat untuk mencapai tujuan bersama dalam kegiatan PLPBK. Kedekatan masyarakat terhadap Ketua RT/RW dipengaruhi oleh ketua RT merupakan orang yang dipercaya masyarakat untuk administrasi tingkat RT/RW serta dipengaruhi oleh jarak tempat tinggal.

Masyarakat yang kurang memiliki keterikatan terhadap RW 04 dapat dilihat dari tidak adanya sesama warga yang memiliki tujuan yang sama meskipun dipengaruhi oleh kedekatan tempat tinggal, namun masyarakat yang memiliki place attachment yang baik cenderung memiliki orang dengan tujuan yang sama karena tempat tinggal yang berdekatan sehingga menimbulkan kesan proximity. Masyarakat yang memiliki orang dengan tujuan sama juga dipengaruhi oleh kesan familiarity yang disebabkan oleh jumlah pertemuan sebanyak 1-2 kali/minggu sebanyak $50,0 \%$.

Keterikatan masyarakat pada suatu tempat setelah pelaksanaan Program PLPBK dapat ditinjau melalui penilaian responden tentang RW 04 yang didominasi oleh penilaian baik sebanyak $83,6 \%$ dengan didominasi alasan menjadi lebih baik karena program PLPBK. Alasan menjadi lebih baik disebabkan karena permukiman kumuh di RW 04 berubah menjadi permukiman yang teratur, aman dan sehat sesuai dengan tujuan PLPBK. Perubahan permukiman di RW 04 menjadi lebih baik dapat mempengaruhi keinginan masyarakat untuk tetap ingin tinggal di RW 04 . Keinginan tetap tinggal juga dipengaruhi oleh kepemilikan rumah pribadi sebesar $82,0 \%$ karena masyarakat merasa memiliki objek 
yang berharga pada RW 04. Kepemilikan rumah sebagai objek yang berharga menjadikan masyarakat lebih terikat pada pada RW 04 sehingga cenderung untuk memiliki usaha bersama dalam melindungi RW 04 bersama dengan orang yang memiliki tujuan yang sama sebesar $88,5 \%$, namun implementasi jenis usaha masyarakat yang didominasi oleh tidak adanya usaha yang dilakukan karena alasan kesibukan kerja sebesar 70,8\%.

Usaha atau tindakan juga dapat mempengaruhi keterikatan masyarakat terhadap suatau tempat (Hinds \& Sparks, 2008) sehingga masyarakat cenderung untuk melakukan keinginan untuk tetap menjaga dan mempebaiki lingkungan RW 04 dipengaruhi oleh usia yang didominasi oleh usia produktif sebesar $89,8 \%$ disebabkan oleh usia produktif lebih sering berkumpul bersama-sama pada malam hari. Suatu tindakan juga dipengaruhi oleh jenis kelamin yang didominasi jenis kelamin laki-laki sebesar 95,7\% karena masyarakat dengan jenis kelamin laki-laki cenderung untuk berkumpul pada malam hari sedangkan jenis kelamin wanita cenderung untuk berkumpul bersama pada pelaksanaan rapat PKK. Tingkat pendapatan juga dapat mempengaruhi masyarakat dalam melakukan tindakan untuk lingkungan RW 04 sehingga masyarakat yang memiliki penghasilan di bawah UMR sebesar $57,1 \%$. Penghasilan di bawah UMR mempengaruhi jenis keterlibatan masyarakat sehingga masyarakat cenderung terlibat menggunakan tenaga dibandingkan dengan membantu pendanaan pada kegiatan PLPBK.

Keterikatan manusia terhadap suatu tempat juga dapat dipengaruhi oleh lama tinggal (Rollero \& De Piccoli, 2010) sehingga semakin lama tinggal masyarakat tinggal pada suatu tempat maka akan semakin memiliki keterikatan yang kuat karena dipengaruhi oleh pertambahan kenangan. Masyarakat yang memiliki place attachment yang kuat didominasi dengan lama tinggal sekitar 5-13 tahun sebesar 32,7\%, namun masyarakat yang memiliki lama tinggal yang $<5$ tahun juga dapat memiliki place attachment yang kuat atau bahkan setara dengan masyarakat yang sudah lama tinggal di RW 04. Kekuatan dari place attachment dipengaruhi oleh tindakan seseorang dalam mengembangkan perasaan keterikatan pada suatu tempat di lingkungan RW 04 seperti kegiatan interaksi sosial. Kemudahan akses juga dapat mempengaruhi keterikatan (Galster, 2001) sehingga RW 04 yang cenderung memiliki akses yang mudah akan memudahkan perpindahan dalam memenuhi kebutuhan sehingga masyarakat menjadikan RW 04 sebagai tempat untuk memenuhi kebutuhan atau disebut dengan place dependence. Place atachment juga dapat ditinjau melalui ikatan emosional masyarakat dengan RW 04 juga dapat dilihat dari keinginan masyarakat dalam melindungi RW 04 yang didominasi oleh keinginan untuk menjadikan RW 04 lebih bersih sehingga jauh dari kesan permukiman kumuh sebesar $57,6 \%$. Tindakan yang dilakukan masyarakat agar menjadi lebih bersih akan mempengaruhi keinginan masyarakat untuk tetap tinggal di RW 04 sebesar 93,0\%, namun masyarakat yang tidak memiliki keinginan untuk tetap tinggal di RW 04 didominasi oleh alasan ingin lingkungan yang lebih baik dari RW 04 sebesar 6,7\%. Kondisi eksisting pada RW 04, Kelurahan Polehan menunjukkan bahwa individu akan semakin melekat atau memiliki place attachment yang kuat seiring dengan semakin sering terjalinnya interaksi sosial, memiliki rumah dengan kepemilikan pribadi sehingga menjadi objek yang dianggap berharga serta semakin sering dalam melakukan tindakan atau usaha untuk mengkontrol lingkungan. Berikut merupakan dimensi tempat yang dapat dilihat pada Tabel 3.

Table 3. Dimensi Tempat

\begin{tabular}{lc}
\hline Place Attachment Masyarakat RW 04 & Persentase \\
\hline $\begin{array}{l}\text { Masyarakat dengan tujuan sama } \\
\text { Tidak }\end{array}$ & $50.7 \%$ \\
$\begin{array}{l}\text { Jenis hubungan dengan Orang Tujuan Sama } \\
\text { Ketua RT/RW }\end{array}$ & $31.9 \%$ \\
$\begin{array}{l}\text { Kedekatan Tempat Tinggal } \\
\text { Tidak ada kedekatan }\end{array}$ & $50.7 \%$ \\
Jumlah Pertemuan dengan Orang Tujuan Sama & $50.0 \%$ \\
\hline
\end{tabular}




\begin{tabular}{|c|c|}
\hline Place Attachment Masyarakat RW 04 & Persentase \\
\hline \multicolumn{2}{|l|}{ Penilaian tentang RW 04} \\
\hline Baik & $83.6 \%$ \\
\hline \multicolumn{2}{|l|}{ Alasan penilaian tentang RW 04} \\
\hline Menjadi Lebih Baik Karena Program PLPBK & $95.4 \%$ \\
\hline \multicolumn{2}{|l|}{ Kepemilikan Rumah } \\
\hline Milik Pribadi & $82.0 \%$ \\
\hline \multicolumn{2}{|l|}{ Usaha Bersama dengan Orang Tujuan Sama } \\
\hline Tidak & $88.5 \%$ \\
\hline \multicolumn{2}{|l|}{ Jenis Usaha dengan Orang Tujuan Sama } \\
\hline Tidak ada & $88.5 \%$ \\
\hline \multicolumn{2}{|l|}{ Alasan Tidak Usaha Memperbaiki RW 04} \\
\hline Sibuk kerja & $70.8 \%$ \\
\hline \multicolumn{2}{|l|}{ Usia } \\
\hline $\begin{array}{l}\text { Usia Produktif } \\
\text { Jenis kelamin }\end{array}$ & $89.8 \%$ \\
\hline Laki-laki & $95.7 \%$ \\
\hline \multicolumn{2}{|l|}{ Lama tinggal } \\
\hline 5-13 tahun & $32.7 \%$ \\
\hline \multicolumn{2}{|l|}{ Pendapatan } \\
\hline Di bawah UMR & $57.1 \%$ \\
\hline \multicolumn{2}{|l|}{ Kemudahan akses } \\
\hline Ya & $100.0 \%$ \\
\hline \multicolumn{2}{|l|}{ Keinginan terhadap RW 4} \\
\hline Menjadikan RW 4 menjadi bersih & $57.6 \%$ \\
\hline \multicolumn{2}{|l|}{ Keinginan tinggal } \\
\hline Ya & $93.0 \%$ \\
\hline \multicolumn{2}{|l|}{ Alasan tidak ingin tinggal } \\
\hline Ingin lingkungan yang lebih baik & $6.7 \%$ \\
\hline
\end{tabular}

\section{Dimensi Psikologi}

Dimensi psikologi dapat mempengaruhi keterikatan masyarakat terhadap tempat yang terbagi menjadi 3 aspek yaitu ikatan afektif, kognitif dan perilaku (Scannell \& Gifford, 2010). Ikatan afektif dapat direpresentasikan melalui perasaan terhadap tempat terhadap tempat dan perasaan wellbeing (kesejahteraan) yang ditandai oleh kondisi yang bahagia dan sejahtera (Brown \& Ryan, 2003). Perasaan masyarakat di RW 04 didominasi oleh perasaan kenyamanan sebesar 93,8\%. Perasaan kenyamanan berdasarkan pada kenangan masa anak-anak yaitu pada sungai karena pada umumnya anak-anak akan cenderung bermain di sungai sebesar 44,8\%. Masyarakat yang berasal dari RW 04 akan memiliki kenangan pada masa anak-anak di Sungai Bango sebesar 28,7\% sedangkan masyarakat yang berada di luar RW 04 akan cenderung terikat dengan sungai di luar RW 04 sebesar $15,8 \%$.

Keterikatan dipengaruhi oleh kenangan yang terbentuk pada masa anak-anak serta tindakan dalam mengontrol (Hinds \& Sparks, 2008). Masyarakat akan mengalami kehilangan suatu tempat ketika tidak dapat menjaga tempat yang dikenang pada masa anak-anak atau tempat yang dikenang mengalami perubahan menjadi lebih buruk, hal tersebut dapat dilihat pada kondisi eksisting yaitu tempat dikenang yang tidak hilang sebesar $77,3 \%$, namun mengalami perubahan menjadi kotor atau dipenuhi sampah sebesar $48,8 \%$. Perubahan menjadi kotor atau dipenuhi sampah pada umumnya dikarenakan aktivitas pembuangan sampah di Sungai Bango karena permukiman di bantaran sungai yang tidak dilayani oleh petugas kebersihan. Masyarakat yang memiliki kenangan kuat pada masa anak-anak akan cenderung mempertahankan kenangan, namun pada RW 04 cenderung untuk membiarkan perubahan sebanyak 69,2\%. Kecenderungan membiarkan perubahan Sungai Bango pada umumnya didominasi oleh masyarakat pendatang sehingga kurang memiliki place attachment pada RW 04 sedangkan masyarakat yang terikat dengan Sungai Bango memiliki usaha agar dapat melindungi atau menjaga melalui usaha tidak membuang sampah di Sungai Bango sebesar 26,3\%. 
Tempat yang dikenang pada umumnya hadir pertama kali pada umur 6-11 tahun sebanyak 90,6\% sehingga kenangan tersebut dapat melekat pada ingatannya hingga dewasa. Suatu tempat yang dikenang tidak terlepas dari objek yang melekat pada suatu tempat yang juga akan mempengaruhi ingatan yang didominasi oleh objek hewan sebesar $72,1 \%$. Objek yang melekat pada suatu tempat dapat mempengaruhi aktivitas responden yang didominasi oleh aktivitas menjelajah berburu hewan sebagai objek yang melekat pada sungai sebesar $67,6 \%$ dengan intensitas bermain setiap hari sebesar $100 \%$.

Keterikatan masyarakat terhadap tempat dapat dipegaruhi oleh asal tempat yang didominasi oleh penduduk asal RW 04 sebesar 72,7\% sehingga masyarakat akan cenderung untuk terikat dengan Sungai Bango sebagai tempat masa anak-anak atau sebagai tempat yang dikenang. Keterikatan masyarakat terhadap RW 04 juga dipengaruhi oleh migrasi yang didominasi oleh pernah melakukan migrasi sebesar 52,8\% sehingga aktivitas migrasi dapat memperlemah place attachment karena berkurangnya waktu yang dihabiskan pada RW 04 atau tidak bertambahnya kenangan pada masa anak-anak. Bertambahnya kenangan pada masyarakat yang cenderung tidak melakukan perpindahan atau berasal dari RW 04 dapat direpresentasikan dengan perasaan kenyamanan ketika bermain bersama teman-teman sebesar $93,8 \%$ sedangkan masyarakat yang berasal dari luar RW 04 cenderung memiliki perasaan bahwa RW 04 tidak dapat menggambarkan masa anak-anak sebesar 52,5\%. Alasan RW 04 tidak dapat menggambarkan masa anak-anak pada responden yang berasal dari luar RW 04 yaitu dapat dipengaruhi oleh tidak terdapat sawah di RW 04 sebesar 35,1\%. Masyarakat yang melakukan perpindahan atau terjadi perubahan dari suatu tempat akan cenderung untuk merenungkan kembali kenangan pada tempat yang dikenang dengan teman masa anak-anak sebesar 100\%. Kondisi eksisting pada RW 04, Kelurahan Polehan menunjukkan bahwa individu akan semakin melekat atau memiliki place attachment yang kuat seiring dengan semakin usaha yang dilakukan, intensitas atau lamanya waktu menghabiskan pada tempat yang dikenang, tidak melakukan perpindahan atau migrasi, RW 04 yang dapat menggantikan atau menggambarkan tempat masa anak-anak pada masyarakat pendatang serta kegiatankegiatan untuk mengenang tempat masa anak-anak. Berikut merupakan dimensi psikologi yang dapat dilihat pada Tabel 4.

Table 4. Dimensi Psikologi

\begin{tabular}{lc}
\hline \multicolumn{1}{c}{ Place Attachment Masyarakat RW 04 } & Persentase \\
\hline Perasaan terhadap tempat & \\
Kenyamanan & $93.8 \%$ \\
Tempat dikenang & \\
Sungai & $44.8 \%$ \\
Lokasi tempat dikenang & \\
Sungai Bango & $28.7 \%$ \\
Keadaan tempat & \\
Berubah menjadi kotor/sampah & $48.8 \%$ \\
Perubahan tempat dikenang & \\
tidak hilang & $77.3 \%$ \\
Usaha agar tidak hilang & \\
Jemis Usaha agar Tidak Hilang & $69.2 \%$ \\
Tidak membuang sampah di Sungai & \\
Waktu pertama kehadiran tempat & $26,3 \%$ \\
SD (6-11 Tahun) & \\
Hewek pada tempat dikenang & $90.6 \%$ \\
Jenis permainan & $72.1 \%$ \\
Menjelajah untuk berburu hewan & \\
Intensitas bermain & $67.6 \%$ \\
Setiap Hari & \\
Rempat asal & $100.0 \%$ \\
\hline
\end{tabular}




\begin{tabular}{lc}
\hline \multicolumn{1}{c}{ Place Attachment Masyarakat RW 04 } & Persentase \\
\hline $\begin{array}{l}\text { Migrasi } \\
\text { Pernah Migrasi }\end{array}$ & $52.8 \%$ \\
$\begin{array}{l}\text { Alasan perasaan } \\
\text { merasakan kenyamanan ketika bermain bersama teman-teman } \\
\text { Tempat yang dapat menggambarkan masa anak-anak }\end{array}$ & $93.8 \%$ \\
$\begin{array}{l}\text { Tidak ada } \\
\text { Alasan RW 04 tidak menggambarkan masa anak-anak } \\
\text { tidak ada alasan }\end{array}$ & $52.5 \%$ \\
$\begin{array}{l}\text { Kegiatan untuk mengenang } \\
\begin{array}{l}\text { Ada kegiatan } \\
\text { Jenis kegiatan mengenang } \\
\text { masih merenungkan kembali bersama teman masa anak-anak }\end{array}\end{array}$ \\
\hline
\end{tabular}

\section{DISKUSI}

Beberapa studi memiliki fokus pada hubungan ikatan antara manusia dengan tempat namun tidak mempertimbangkan proses terjadinya ikatan hingga muncul place attachment yang kuat. Pada studi ini menemukan bahwa proses menjadi salah satu indikator yang penting dalam suatu hubungan antara manusia dengan suatu tempat. Proses yang terjadi secara alami berdasarkan The Tripartite Model of Place Attachment termasuk ke dalam dimensi proses yang terbagi menjadi 3 yaitu afektif, kognitif dan perilaku. The Tripartite Model of Place Attachment juga terdiri dari dimensi pelaku yang diklasifikasikan menjadi pelaku individu dan pelaku kelompok serta dimensi tempat yang diklasifikasikan menjadi aspek fisik dan aspek sosial. Kerangka dari The Tripartite Model of Place Attachment yang digunakan dari penelitian sebelumnya dapat menunjang penelitian Place Attachment Masyarakat di RW 04, Kelurahan Polehan, Kota Malang sehingga menghasilkan gambaran tentang place attachment pada RW 04 setelah dilaksanakannya PLPBK. Place attachment pada RW 04 dapat dijelaskan sesuai dengan dimensi sebagai berikut.

1. Konsep dimensi pelaku diklasifikasikan menjadi pelaku individual dan pelaku komunal yang dalam penelitian ini keduanya memiliki peran yang penting dalam meninjau keterikatan masyarakat terhadap RW 04. Dimensi pelaku berdasarkan pada pengalaman menunjukkan bahwa masyarakat yang memiliki pengalaman pada masa anak-anak di wilayah RW 04 akan semakin memiliki place attachment yang kuat pada RW 04 serta interaksi sosial yang dilakukan melalui perayaan lokal di RW 04

2. Konsep dimensi tempat yang diklasifikasikan menjadi aspek fisik dan aspek sosial yang dalam penelitian ini keduanya memiliki peran yang penting dalam meninjau keterikatan masyarakat terhadap RW 04. Dimensi tempat berdasarkan pada interaksi sosial, memiliki rumah dengan kepemilikan pribadi sehingga menjadi objek yang dianggap berharga serta semakin sering dalam melakukan tindakan atau usaha untuk mengkontrol lingkungan

3. Konsep dimensi proses psikologi yang diklasifikasikan menjadi afektif, kognitif dan perilaku yang memiliki peran yang penting dalam meninjau keterikatan mayarakat terhadap RW 04. Dimensi proses psikologi berdasarkan pada usaha yang dilakukan, intensitas atau lamanya waktu menghabiskan pada tempat yang dikenang, tidak melakukan perpindahan atau migrasi, RW 04 yang dapat menggantikan atau menggambarkan tempat masa anak-anak pada masyarakat pendatang serta kegiatankegiatan untuk mengenang tempat masa anak-anak

\section{KESIMPULAN}

Keterikatan masyarakat pada RW 04 dapat ditinjau melalui The Tripartite Model of Place Attachment yang diklasifikasikan menjadi dimensi pelaku, tempat dan proses psikologi. Berdasarkan pada kondisi eksisting di RW 04, Kelurahan Polehan menunjukkan 
bahwa individu akan semakin melekat atau memiliki place attachment yang kuat seiring dengan individu yang mengembangkan perasaan-perasaan pada RW 04 atau dengan meningkatkan indikator-indikator pada dimensi pelaku, tempat dan proses psikologi. Kekuatan place attachment juga dapat mempengaruhi masyarakat dalam memiliki perasaan sense of belonging pada pembangunan fisik yang dilaksanakan dalam Program PLPBK. Sense of belonging diharapkan agar masyarakat ikut terlibat melindungi program agar berlangsung secara berkelanjutan dan tepat sasaran.

Keterikatan masyarakat setelah pelaksanaan Program PLPBK memiliki ikatan yang kuat karena masyarakat merasa bahwa lingkungan RW 04 menjadi lingkungan yang asri, nyaman dan aman serta memiliki perasaan yang sama saat masa anak-anak meskipun terjadi perubahan guna lahan. Objek utama di RW 04 dikenang adalah Sungai Bango yang juga menjadi bagian penting dari Program PLPBK sehingga masyarakat cenderung untuk menjaga dan melindungi Sungai Bango agar terlihat bersih dan tidak terdapat penumpukan sampah. Pembangunan dalam Program PLPBK yang bersinggungan dengan sungai sebagai objek yang penting dapat menjadi sustainable. Program PLPBK dapat merubah kesan kumuh menjadi kesan yang indah sehingga memperkuat place attachment, oleh karena itu masyarakat cenderung memiliki keinginan untuk tetap tinggal di RW 04.

\section{DAFTAR PUSTAKA}

Altman, I., \& Low, S. M. (1992). Place Attachment. https://doi.org/10.1007/978-1-4684-8753-

Brown, K. W., \& Ryan, R. M. (2003). The Benefits of Being Present: Mindfulness and Its Role in Psychological Well-Being. Journal of Personality and Social Psychology, 84(4), 822-848. https://doi.org/10.1037/00223514.84.4.822

Casakin, H., Hernández, B., \& Ruiz, C. (2015). Place attachment and place identity in Israeli cities: The influence of city size. Cities, 42(PB), 224-230. https://doi.org/10.1016/j.cities.2014.07.007

Dayakisni, T., \& Hudainah. (2015). Psikologi Sosial. UMMI Press.

Galster, G. (2001). On the nature of neighbourhood. Urban Studies, 38(12), 2111-2124. https://doi.org/10.1080/00420980120087072

Hinds, J., \& Sparks, P. (2008). Engaging with the natural environment: The role of affective connection and identity. Journal of Environmental Psychology, 28(2), 109-120. https://doi.org/10.1016/j.jenvp.2007.11.001

Kaltenborn, B. P., \& Bjerke, T. (2002). Association between environmental value orientations and landscape preferences. Landscape and Urban Planning, 59(1), 1-11. https://doi.org/10.1016/S0169-2046(01)00243-2

Kilinç, M. (2006). Institutional Environment and Place Attachment as Determinants of Elders' Life Satisfaction. Journal of Psychology, 22(9), 107-119.

Lewicka, M. (2010). What makes neighborhood different from home and city? Effects of place scale on place attachment. Journal of Environmental Psychology, 30(1), 35-51. https://doi.org/10.1016/j.jenvp.2009.05.004

Morgan, P. (2010). Towards a developmental theory of place attachment. Journal of Environmental Psychology, 30(1), 11-22. https://doi.org/10.1016/j.jenvp.2009.07.001

Pemerintah Kota Malang. (2015). Penyusunan Rencana Aksi Malang Tanpa Kumuh. Malang.

Rofiana, V. (2015). DAMPAK PEMUKIMAN KUMUH TERHADAP KELESTARIAN LINGKUNGAN KOTA MALANG (Studi Penelitian di Jalan Muharto Kel Jodipan Kec Blimbing, Kota Malang. The Indonesian Journal of Public Administration (IJPA), 1(1), 40-57. Retrieved from http://journal.uta45jakarta.ac.id/index.php/admpublik/article/view/73

Rollero, C., \& De Piccoli, N. (2010). Place attachment, identification and environment perception: An empirical study. Journal of Environmental Psychology, 30(2), 198-205. https://doi.org/10.1016/j.jenvp.2009.12.003

Scannell, L., \& Gifford, R. (2010). Defining place attachment: A tripartite organizing framework. Journal of Environmental Psychology, 30(1), 1-10. https://doi.org/10.1016/j.jenvp.2009.09.006

Wynveen, C. J., Kyle, G. T., \& Sutton, S. G. (2012). Natural area visitors' place meaning and place attachment ascribed to a marine setting. Journal of Environmental Psychology, 32(4), 287-296. https://doi.org/10.1016/j.jenvp.2012.05.001 